\title{
Investigating the relationship between welfare and rearing young in captive chimpanzees (Pan troglodytes)
}

\author{
Katherine A. Cronin ${ }^{a, b}, *$, Victoria West ${ }^{c}$, Stephen R. Ross ${ }^{a}$ \\ ${ }^{a}$ Lester E. Fisher Center for the Study and Conservation of Apes, Lincoln Park Zoo, Chicago, IL, USA \\ b Comparative Cognitive Anthropology Group, Max Planck Institute for Psycholinguistics, Nijmegen, The Netherlands \\ ${ }^{c}$ Centre for Behaviour and Evolution, Institute of Neuroscience, Newcastle University, Newcastle upon Tyne, United Kingdom
}

\section{A R T I C L E I N F O}

\section{Article history:}

Received 21 October 2015

Received in revised form 14 April 2016

Accepted 15 May 2016

Available online 19 May 2016

\begin{abstract}
A B S T R A C T
Whether the opportunity to breed and rear young improves the welfare of captive animals is currently debated. However, there is very little empirical data available to evaluate this relationship and this study is a first attempt to contribute objective data to this debate. We utilized the existing variation in the reproductive experiences of sanctuary chimpanzees at Chimfunshi Wildlife Orphanage Trust in Zambia to investigate whether breeding and rearing young was associated with improved welfare for adult females $(\mathrm{N}=43)$. We considered several behavioural welfare indicators, including rates of luxury behaviours and abnormal or stress-related behaviours under normal conditions and conditions inducing social stress. Furthermore, we investigated whether spending time with young was associated with good or poor welfare for adult females, regardless of their kin relationship. We used generalized linear mixed models and found no difference between adult females with and without dependent young on any welfare indices, nor did we find that time spent in proximity to unrelated young predicted welfare (all fullnull model comparisons likelihood ratio tests $P>0.05$ ). However, we did find that coprophagy was more prevalent among mother-reared than non-mother-reared individuals, in line with recent work suggesting this behaviour may have a different etiology than other behaviours often considered to be abnormal. In sum, the findings from this initial study lend support to the hypothesis that the opportunity to breed and rear young does not provide a welfare benefit for chimpanzees in captivity. We hope this investigation provides a valuable starting point for empirical study into the welfare implications of managed breeding.

(C) 2016 Elsevier B.V. All rights reserved.
\end{abstract}

\section{Introduction}

Because captive populations of animals have a finite amount of space available, managers consider regulating population growth by limiting breeding and, consequently, opportunities to rear young. Across zoos and sanctuaries worldwide, approaches vary between (1) complete breeding restriction, (2) regulated breeding of recommended individuals, and (3) unregulated breeding. Decisions about if and how to manage breeding most often revolve around issues of available space, demographic makeup and genetic diversity of the captive population, or reproductive health (Ballou et al., 2010; Leus et al., 2011; Penfold et al., 2014). Here, we focus on an additional consideration that has received less scientific

\footnotetext{
* Corresponding author at: Lester E. Fisher Center for the Study and Conservation of Apes, Lincoln Park Zoo, Chicago, IL, USA.

E-mail addresses: kcronin@lpzoo.org, katie.a.cronin@gmail.com (K.A. Cronin).
}

attention, namely, the impact of breeding and rearing young on individual welfare.

Some argue that replicating as much as possible wild or "natural" activities is a way to maximize positive welfare for animals in captive conditions (see discussion in Penfold et al., 2014). In support of this perspective, research across varying taxa has demonstrated that a lack of ability to express species-typical behavioural patterns such as traveling and grooming are associated with compromised welfare (e.g., Clubb and Mason, 2003, 2007; Pomerantz et al., 2013; Vestergaard et al., 1997).

Whether limiting other social behaviours, specifically breeding and raising young, is associated with compromised welfare is unknown. The degree to which the opportunity to breed and rear young is related to animal welfare is a contemporary consideration among animal population managers (Powell, 2014) and the ramifications of those decisions are broadly and publically debated. The highest profile example of this was the justification of euthanizing a giraffe at the Copenhagen Zoo (Denmark) in 2014. This was one highly publicized example of managers ascribing substantial 
Table 1

Minimum estimates of the number of chimpanzees in captivity worldwide.

\begin{tabular}{ll}
\hline Location & Est. Population (source) \\
\hline $\begin{array}{l}\text { Zoos accredited by the Association of Zoos and } \\
\text { Aquariums (North America) }\end{array}$ & $275(1)$ \\
$\begin{array}{l}\text { Unaccredited North American institutions } \\
\text { Sanctuaries accredited by the Global }\end{array}$ & $131(1)$ \\
$\begin{array}{l}\text { Federation of Animal Sanctuaries } \\
\text { Zoos accredited by the European Association of }\end{array}$ & $759(1)$ \\
$\begin{array}{l}\text { Zoos and Aquaria } \\
\text { Unaccredited European institutions }\end{array}$ & $291(2)$ \\
$\begin{array}{l}\text { Sanctuaries accredited by the Pan African } \\
\text { Sanctuary Alliance } \\
\text { Sanctuaries accredited by the Global }\end{array}$ & $867(3)$ \\
$\begin{array}{l}\text { Federation of Animal Sanctuaries } \\
\text { Total }\end{array}$ & $559(1)$ \\
\hline
\end{tabular}

Sources: (1) www.chimpcare.org; (2) European Chimpanzee Studbook, 2014, compiled by F. Carlsen \& T. de Jongh; (3) Compiled from the websites of the sanctuaries listed as accredited by the Pan African Sanctuary Alliance (www.pasa.org) as of 12 August 2015 (only those housing chimpanzees are listed): Ape Action Africa (Cameroon, http://apeactionafrica.org); Centre pour Conservation des Chimpanzees (Guinea, http://www.projetprimates.com); Chimfunshi Wildlife Orphanage Trust (Zambia, www.chimfunshi.de); Chimpanzee Rehabilitation Project (Gambia, http:// www.friendsofanimals.org); HELP-Congo (Congo, www.help-primates.org); Jane Goodall Institute Chimpanzee Eden (South Africa, www.chimpeden.com); Jeunes Animaux Confisques au Katanga J.A.C.K. (Democratic Republic of Congo, www. jacksanctuary.org); Limbe Wildlife Centre (Cameroon, www.limbewildlife.org); Lwiro Primate Rehabilitation Centre (Democratic Republic of Congo, lwiroprimates.org); Chimpanzee Sanctuary and Wildlife Conservation Trust Ngamba Island (Uganda, www.ngambaisland.com); Sanaga-Yong Chimpanzee Rescue Center (Cameroon, http://www.ida-africa.org); Sweetwaters Chimpanzee Sanctuary (Kenya, http://www.olpejetaconservancy.org); Tacugama Chimpanzee Sanctuary (Sierra Leone, www.tacugama.com) Tchimpounga Chimpanzee Rehabilitation Centre (Congo, http://www.janegoodall.org/programs/tchimpounga-chimpanzeerehabilitation-center)

behavioural benefit to the natural act of breeding and parenting; in this case the presumed benefit of breeding justified the humane euthanasia of healthy offspring. With this context, it seems critical to discern the true behavioural benefit of these behaviours to captive animals to help inform future management practices.

As the opportunity to breed and rear young may affect different species in different ways, we choose to begin this investigation in a single species common to zoos and sanctuaries across the world, chimpanzees (Pan troglodytes). At least 3400 chimpanzees are currently managed in captivity worldwide (Table 1 ). Given the sheer number of chimpanzees in captive management and their capacity for long-term and complex social relationships (Hirata, 2009; Lehmann and Boesch, 2009), this species is a high priority for investigating how rearing young may impact welfare. Furthermore, the number of chimpanzees in sanctuaries may continue to increase as illegal trade continues to produce orphans in need of long-term homes (Ghobrial et al., 2010) and sanctuaries provide a home for chimpanzees retiring from research. In the wild, chimpanzees spend much of their adult life rearing offspring (Pusey and Schroepfer-Walker, 2013), can show marked behavioural responses to the death of offspring (Biro et al., 2010; Cronin et al., 2011; Matsuzawa, 1997), and interactions with young are associated with changes in maternal physiology and behaviour (Murray et al., 2014; Pusey, 1983; Stanton et al., 2015). Yet, to our knowledge, whether employing captive management strategies that restrict breeding and rearing young are associated with compromised welfare has not yet been objectively assessed.

Welfare is a multi-faceted concept that cannot be adequately measured with a single approach (Dawkins, 1998; Mason and Mendl, 1993). We focused not only on abnormal and stress-related behaviours often used to gauge welfare (e.g., Llorente et al., 2015; Pomerantz and Terkel, 2009) but also on a potential positive welfare indicator, play, in line with the increased interest in welfare science paradigms that include positive outcomes (Mellor et al., 2009;
Mellor, 2015). Play has been proposed as one of the most promising positive welfare indicators because it is more likely to be performed when animals are experiencing positive affective states, the behaviour is linked with positive emotions, and it is reduced when animals are faced with poor conditions (Boissy et al., 2007; Held and Špinka, 2011). Finally, we included an additional welfare assessment that was based on research demonstrating that individuals with compromised welfare are poorly equipped to handle stressors (Boccia et al., 1995; Moberg, 2000). Specifically, we measured the frequency of abnormal and stress-related behaviours expressed by chimpanzees anticipating an arousing situation, social feeding in a constrained space.

Given that direct paternal care is virtually absent among chimpanzees (Lehmann et al., 2006; Pusey, 1983), we focused on females in order to obtain information on welfare differences that may result from reproducing and being a primary caregiver. Additionally, the presence of young in a group may affect the welfare of chimpanzees even if the young are not their own biological offspring, for example by stimulating a more dynamic and active social environment. Therefore, we extended our research focus to ask whether the welfare of females is impacted by interaction with young that are not necessarily their own biological offspring. We included this secondary question in order to begin to evaluate whether limited breeding in a chimpanzee group may positively or negatively impact the welfare of other, non-breeding females in the social group.

This study took place at Chimfunshi Wildlife Orphanage Trust in Zambia. Contraception for female chimpanzees at Chimfunshi has occurred on an opportunistic and irregular schedule, with some but not all adult females receiving subcutaneous hormone implants to interrupt reproductive cycling. Therefore, there is currently a mix of reproductive experiences among the adult female chimpanzees at Chimfunshi. The existing variation allowed us to investigate whether the opportunity to rear young had an effect on the welfare of female chimpanzees without experimentally manipulating any chimpanzees' reproductive status.

\section{Methods}

\subsection{Study site and subjects}

Chimfunshi Wildlife Orphanage Trust (Chimfunshi) is a nonprofit sanctuary in the Copperbelt region of Northern Zambia $\left(12^{\circ} 23^{\prime} \mathrm{S}, 29^{\circ} 32^{\prime} \mathrm{E}\right)$ on 24,000 acres of miombo woodland forest suitable for chimpanzees (Ron and McGrew, 1988). The chimpanzees that were the focus of this study lived in four separate social groups to which no new individuals had been introduced for at least ten years. Each group was comprised of a mix of wild-born (confiscated and human-reared) and captive-born (mother-reared) individuals. At Chimfunshi, the chimpanzees remain in outdoor enclosures at all times except for two hours mid-day when they enter a building for observational health monitoring and supplemental feeding. Four groups were the focus of this study; the groups ranged in size from 10 to 46 individuals and the enclosure sized ranged from 19 to 77 ha. Demographic compositions of the social groups are available in Table 2. Given that chimpanzees may nurse through six years of age (Goodall, 1986; Nishida, 2011), we opted to consider individuals $<7$ years of age as "dependent young" that may influence the welfare of others. The number of dependent young per group ranged between 3 and 12 across groups.

\subsection{Welfare indicators}

\subsubsection{Weekly rates of abnormal or stress-related behaviours $\mathcal{E}$ luxury behaviours (play)}

Observations were conducted for one hour per enclosure per day while the chimpanzees were in their outdoor enclosure, with 
Table 2

Demographic composition of the groups at the start of the study (October 2014).

\begin{tabular}{|c|c|c|c|c|}
\hline & Group 1 & Group 2 & Group 3 & Group 4 \\
\hline Adult females with dependent young & 4 & 9 & 1 & 1 \\
\hline Adult females without dependent young & 6 & 17 & 3 & 2 \\
\hline Adult males & 8 & 8 & 3 & 6 \\
\hline Dependent young & $6(2.4)$ & $12(3.9)$ & $3(1.2)$ & $3(3.0)$ \\
\hline Total group size & $24(10.14)$ & $46(11.35)$ & $10(4.6)$ & $12(9.3)$ \\
\hline Wild-born individuals & $7(4.3)$ & $15(3.12)$ & $6(2.4)$ & $7(5.2)$ \\
\hline
\end{tabular}

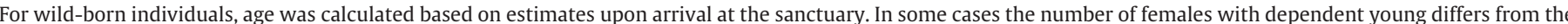

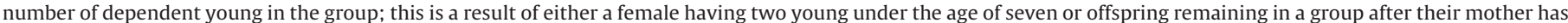
died. The number of males and females is shown in parentheses (male $\times$ female).

an equal number of morning and afternoon observations per enclosure. Chimfunshi chimpanzees live in large forested habitats surrounded by an electric fence; researchers follow a strict nocontact policy and all observations are conducted from outside the fence. Therefore, observational methods have been developed to allow for systematic observational data collection in this environment where following the animals is impeded (Cronin et al., 2014; van Leeuwen et al., 2012). Briefly summarized, the observer started an observation session at a randomly pre-chosen location around the enclosure edge. If no chimpanzees were visible, the observer started searching in randomised direction along the fence line and began a focal follow on the first chimpanzee observed. After the initial focal follow was complete, the next focal follow was conducted on the nearest chimpanzee not already followed for $10 \mathrm{~min}$ that day. For the current study, potential focal subjects included any female $\geq 7$ years.

Behavioural data were collected by 10 -min focal follows with scans every minute. At one-minute intervals, the observer indicated the presence/absence of behaviours in the ethogram (Table 3) and the identity of any individuals less than 7 years of age within $2 \mathrm{~m}$. Data collection for this study took place over a ten-week period from October 2 to December 4, 2014.

\subsubsection{Response to social challenge}

The Chimfunshi chimpanzees are exposed to a moderate stressor daily, namely, entering a building for supplemental feeding. Social feeding has been shown to be an arousing situation for chimpanzees both behaviourally and physiologically (Wobber et al., 2010). At the same time every day, social groups are verbally called inside an attached building through two shift doors into a series of adjacent rooms in which they receive food. Many Chimfunshi chimpanzees anticipate this event and begin to gather around the building several minutes prior to the time that the building doors are opened. At the time that the chimpanzees are called inside, there is a notable increase in arousal indicated by increased physical contact, pant hoots and visual displays (Cronin, personal observation). For this study, we recorded the frequency of abnormal or stress-related behaviours expressed during the $30 \mathrm{~min}$ before the chimpanzees were closed indoors. Using scan sampling with oneminute intervals, we coded the presence (visibility) of each subject and the occurrence of abnormal or stress-related behaviours as listed in the ethogram (Table 3 ) during this social challenge.

\subsection{Data analysis}

For each of the welfare indicators we created generalized linear mixed models (GLMMs) that included subjects, social group and age as random factors and female reproductive category (with or without dependent young) as a dichotomous fixed factor, given that our primary question of interest was whether reproductive category predicted welfare. For the analyses of behaviours observed during focal follows, we used weekly rates of behaviours (\# instances observed/\# minutes in view). Age and origin were not indepen-
Table 3

Ethogram of luxury and abnormal or stress-related behaviours.

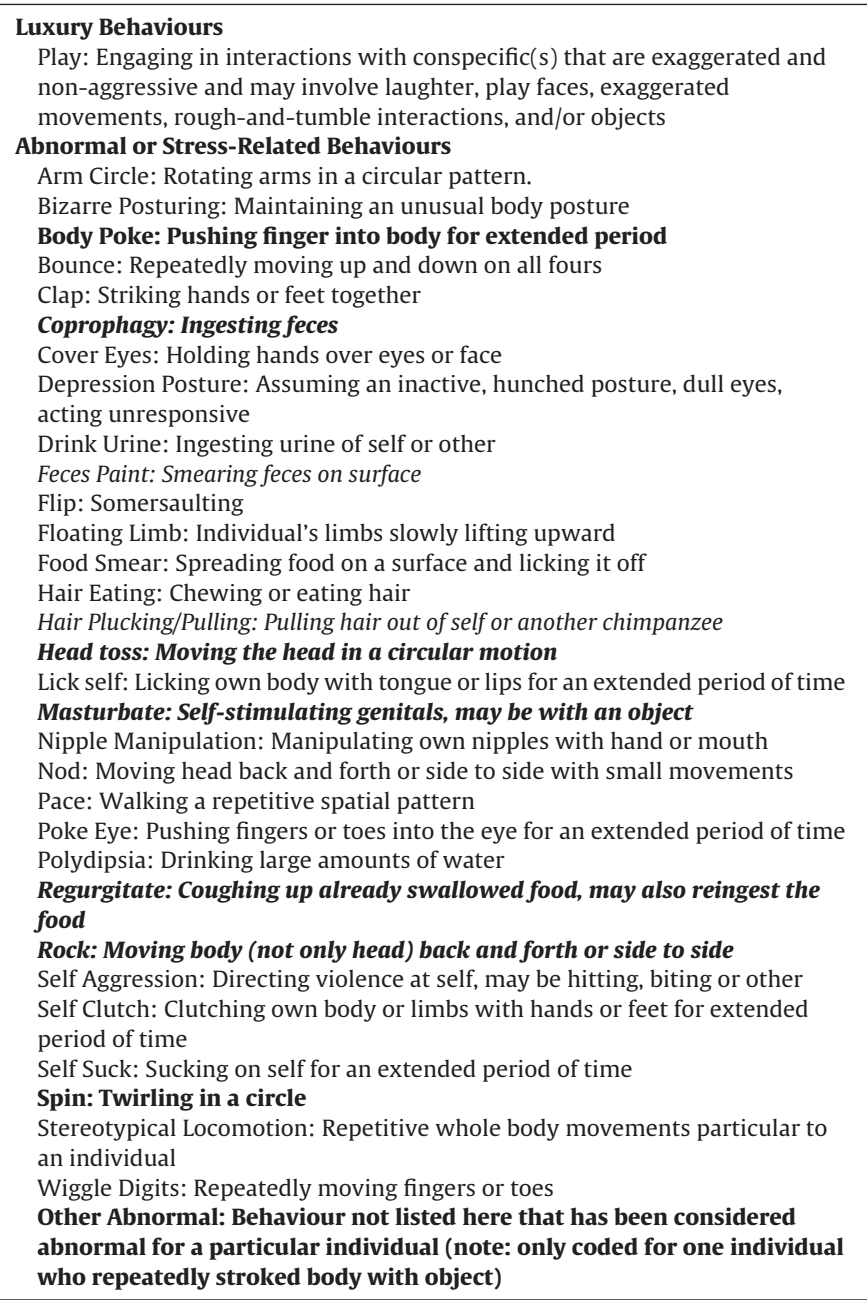

Behaviours observed during social challenge indicated in bold; behaviours observed in focal follows indicated in italics.

dent; wild-born individuals tend to be older than captive born individuals at Chimfunshi (average age wild-born $=26.2$, captive born $=14.3$ years). Therefore, we included (mean-centered) age in the models and additionally provide nonparametric tests of differences between captive and wild-born individuals for each of the welfare indicators, employing Bonferonni correction for multiple comparisons (adjusted alpha $=0.0125$ ). To address our secondary question of whether time spent in proximity to young was associated with welfare indicators, we created GLMMs with subjects, social group and (mean-centered) age as random factors and proportion in-view scans in which the focal was in proximity to at least one individual $<7$ years as a continuous fixed factor. To avoid over- 
fitting the models, we did not nest subjects within social groups but instead included subjects and social groups separately. Likelihood ratio tests using the anova function and chi-square distribution were used to compare full models with null models excluding reproductive category or time spent in proximity to young. Analyses were conducted using R version 3.10 (R Core Team, 2014), with mixed-effects models calculated using the lme4 package (Bates et al., 2014).

\section{Results}

A total of $5423 \mathrm{~min}$ of (in view) focal follow data were collected on 43 adult females over the ten-week observation period. The average duration of observation time for adult females was $126 \pm 12$ (range $2-328$ ) $\mathrm{min}$. At the start of data collection, the average age of the adult females was 19.6 years (range $8-37$ years; note ages of wild-born individuals are estimates) and the average age of the dependent young was 4.1 years (range $0-7$ years).

The number of adult females without and with current dependent young was 28 and 15, respectively. The median age of females without dependent young was 18.8 years (range $7.8-37.8$ ) and the median age of females with dependent young was 22.5 years (range 12.4-31.8). Of the females without dependent young, 57\% were wild-born whereas $40 \%$ of the females with dependent young were wild-born.

\subsection{Reproductive experience and welfare indicators, GLMM}

Full-null model comparison indicated that female reproductive category was not a significant predictor of any of the following welfare indicators: weekly rate of abnormal or stress-related behaviours $\left(\chi^{2}{ }_{1}=0.387, P=0.844\right.$; Fig. $\left.1 \mathrm{a}\right)$, weekly rate of play $\left(\chi^{2}{ }_{1}=0.095, P=0.758\right.$; Fig. $\left.1 \mathrm{~b}\right)$, nor the rate of abnormal or stressrelated behaviours in response to the social challenge $\left(\chi^{2}{ }_{1}=0.720\right.$, $P=0.396$; Fig. 1c.). Full model results are available in the Supplementary materials, models $1 \mathrm{a}-\mathrm{c}$. There was one outlier in the social challenge data (rate of abnormal behaviour more than 4 SD above mean); exclusion of this data point did not affect model results $\left(\chi^{2}{ }_{1}=0.837, P=0.360\right)$.

Non-parametric Mann-Whitney tests were used to compare welfare indicators between wild-born (non-mother reared) and captive-born (mother-reared) individuals. There were no significant differences between groups for weekly rate of abnormal or stress-related behaviours $(U=191, P=0.284)$ nor for weekly rate of play $(U=218, P=0.692)$. There was however a significant difference between captive and wild-born individuals for rate of abnormal or stress-related behaviours in response to the social challenge $(U=109.5, P<0.001)$. Captive-born females showed more abnormal or stress-related behaviours than wild-born individuals (median captive-born $=0.008$ events $/ \mathrm{min}$; wild-born 0.000 events/min). Further inspection of these results revealed that of the 84 behavioural events observed, 57 (68\%) were coprophagy.

\subsection{Time spent in proximity to young and welfare indicators}

As expected, adult females with dependent young were observed to spend more time in proximity to young than those without, not considering kinship (median proportion of scans in proximity to individuals younger than 7 years: females with dependent young $=0.80$, females without $=0.30$, Mann Whitney $U=43$, $P<0.01$, Fig. 2).

However, full-null model comparisons indicated that time spent in proximity to young was not a significant predictor of any of the following welfare indicators: weekly rate of abnormal or stressrelated behaviours $\left(\chi_{1}^{2}=0.856, P=0.355\right.$; Fig. $\left.3 a\right)$, weekly rate of play $\left(\chi^{2}{ }_{1}=0.772, P=0.380\right.$; Fig. $\left.3 b\right)$, nor the rate of abnormal

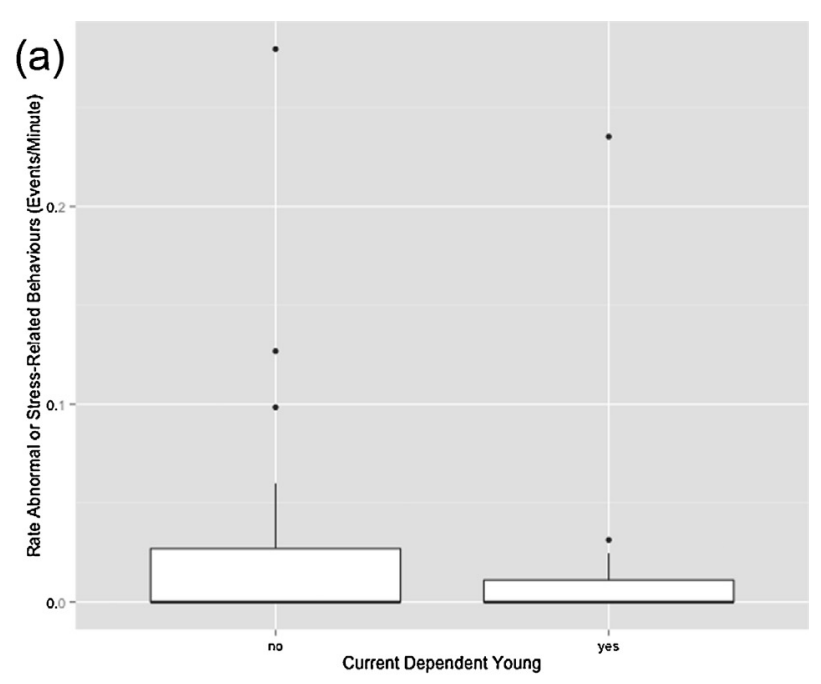

(b)

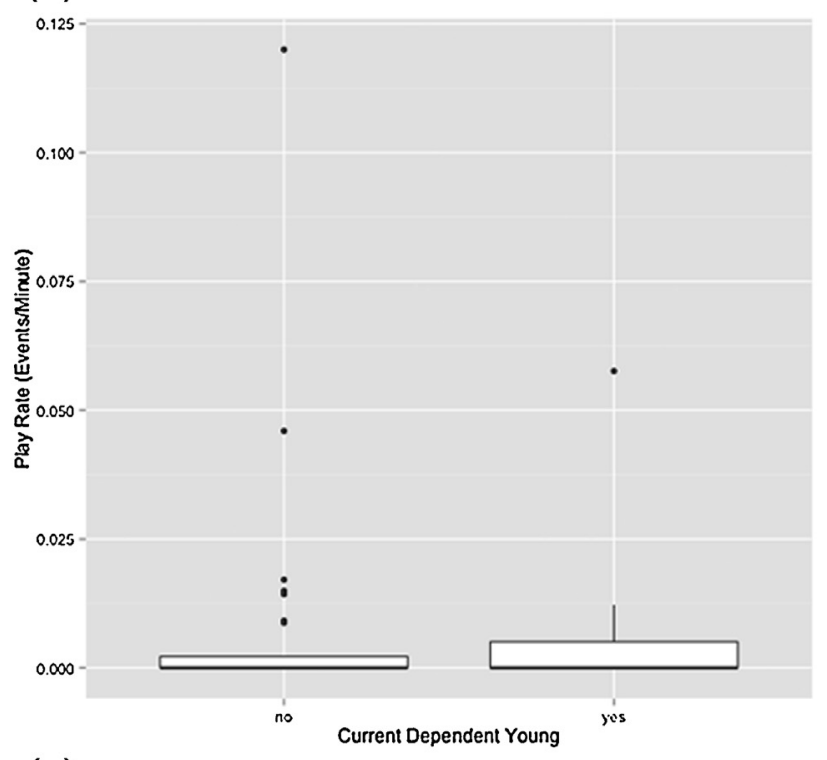

(c)

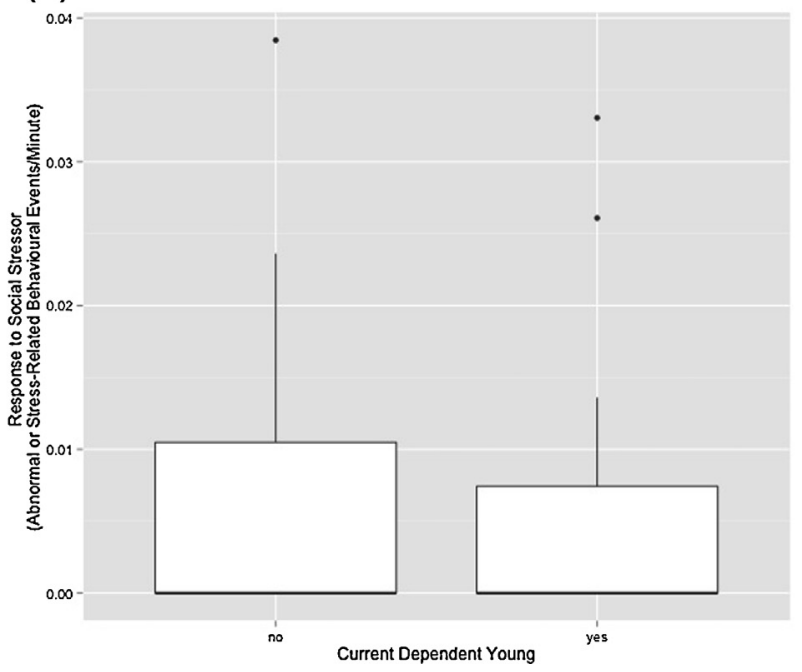

Fig. 1. a-c Boxplots showing rates of behaviour for females with and without current dependent young. In each boxplot, the dark horizontal bar represents the median value, the white box encompasses the 25th to 75th percentile, the whiskers extend to the maximum and minimum values, and outliers shown as separate points. The extreme outlier reported in the results is excluded from $\mathrm{c}$ to improve visualization. Whether females did or did not have dependent young was not a significant predictor of any of these behavioural measures (all $P>0.4$ ). 


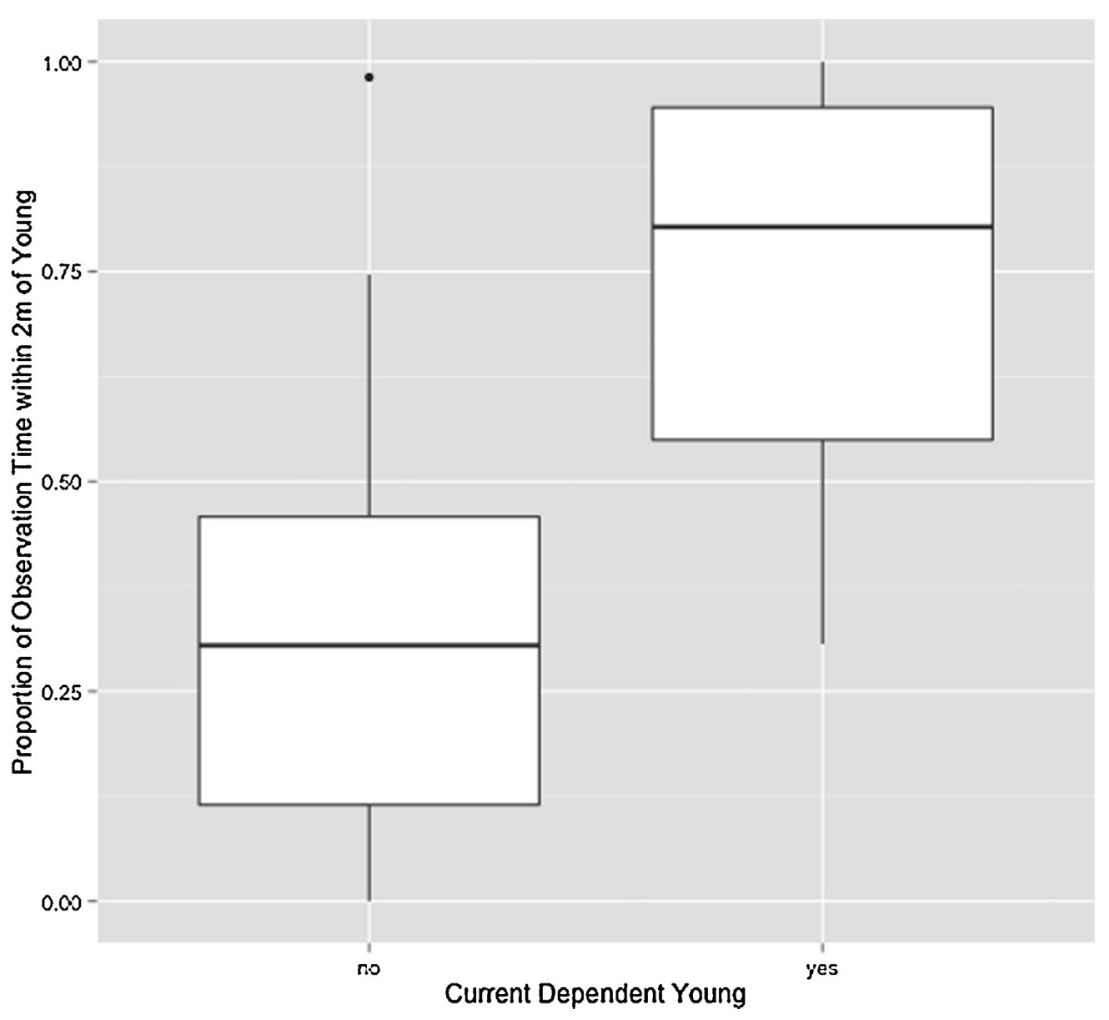

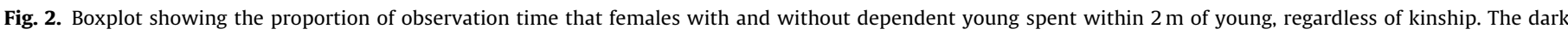

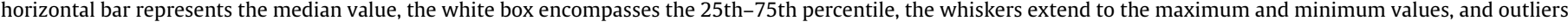
shown as separate points. The difference is statistically significant $(P<0.01)$.

or stress-related behaviours in response to the social challenge $\left(\chi^{2}{ }_{1}=0.059, P=0.808\right.$; Fig. $\left.3 c\right)$. Full model results are available in the Supplementary materials, models $2 \mathrm{a}-\mathrm{c}$. Again, exclusion of the outlier in the social challenge data did not affect model results $\left(\chi^{2}{ }_{1}=0.038, P=0.845\right)$.

\section{Discussion}

We attempted to quantitatively assess whether rearing young is associated with measurable differences in welfare in chimpanzees. Objective information regarding if and how breeding and rearing young impacts welfare is needed in order to empower managers and conservation planners to make informed decisions about regulating reproduction in captive populations (Plowman et al., 2005). Chimpanzees are an important species with which to begin addressing the relationship between welfare and reproduction because they are highly represented in captivity, have well-developed cognitive capacities, and form long-lasting motheroffspring bonds.

Here, we specifically measured how currently having dependent young, or associating with young, was related to welfare indicators. In a sense these each serve as proxies for rearing young and admittedly we did not tackle how other behaviours associated with rearing (e.g. carrying, nursing) impact welfare. None the less, our findings support the hypothesis that allowing chimpanzees the opportunity to rear young does not provide a welfare benefit. We found no differences between adult females with and without current dependent young for any of the behavioural welfare indicators we evaluated. It could be argued that having young in the group can improve the welfare of others by enriching the social environment, yet we found no evidence that associating with young improved the welfare of others in the group. Although this conclusion comes with several caveats discussed below, this first objective assessment of the relationship between welfare and rearing young provides no support for the perspective that allowing female chimpanzees to breed and rear young will enhance their welfare, nor the welfare of others in the group.

At Chimfunshi, all groups contain some young individuals. Therefore, we are unable to address how the complete absence of young in a group may influence welfare. Future work, perhaps utilizing a multi-institutional comparative approach, could address welfare differences across groups with and without the youngest age classes represented to begin to address this limitation. Another fruitful future direction that does not involve experimental manipulation of reproductive capabilities could be to take a longitudinal approach and track females over time, especially in populations where females are provided contraception during some but not all of their adult life. A long-term dataset would also allow for sampling that may better maximize the independence of behavioural observations and allow researchers to disentangle abnormal behaviours that may be a result of reproductive experience from those that were present prior to the onset of reproductive maturity. It will also be imperative to broaden the scope of welfare measures (for example to include hormonal and psychological indicators; e.g., Bethell, 2015; Palme, 2012). Although we included several measures here, we were limited to the behavioural domain in this initial study.

Moving forward, it will also be important to consider how rearing young influences gregariousness (Murray et al., 2014) or social integration. In many primate species, individuals are attracted to young and mothers with dependent young seem to be more attractive social partners (Hrdy, 1976; Silk, 1999), and, at least among humans, there are direct links between social support and both psychological and physical welfare (Thoits, 2011; Uchino et al., 1996). Group-level cohesion and individual differences in social integration could be assessed through social network analysis within and between primate groups (e.g., Cronin et al., 2014). 


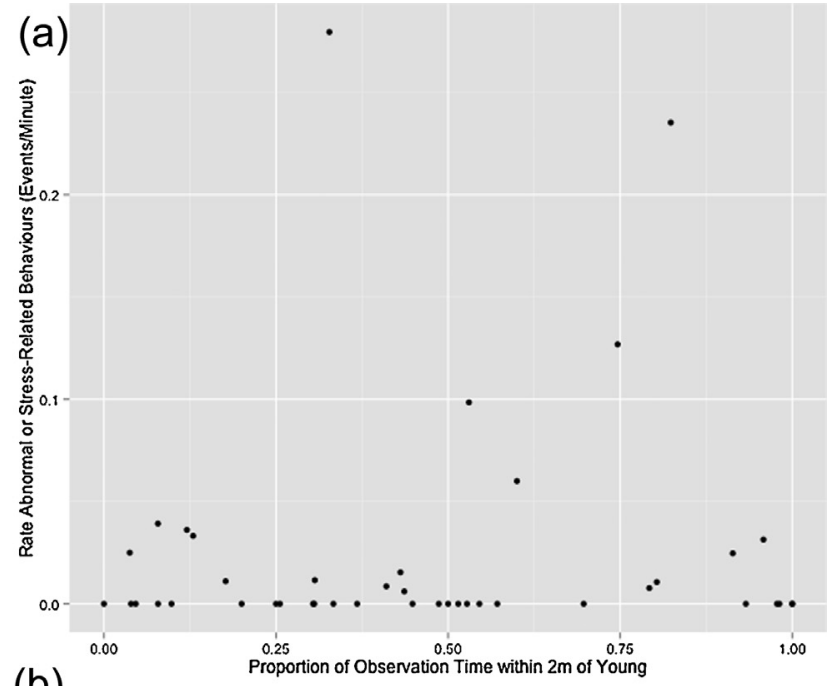

(b)

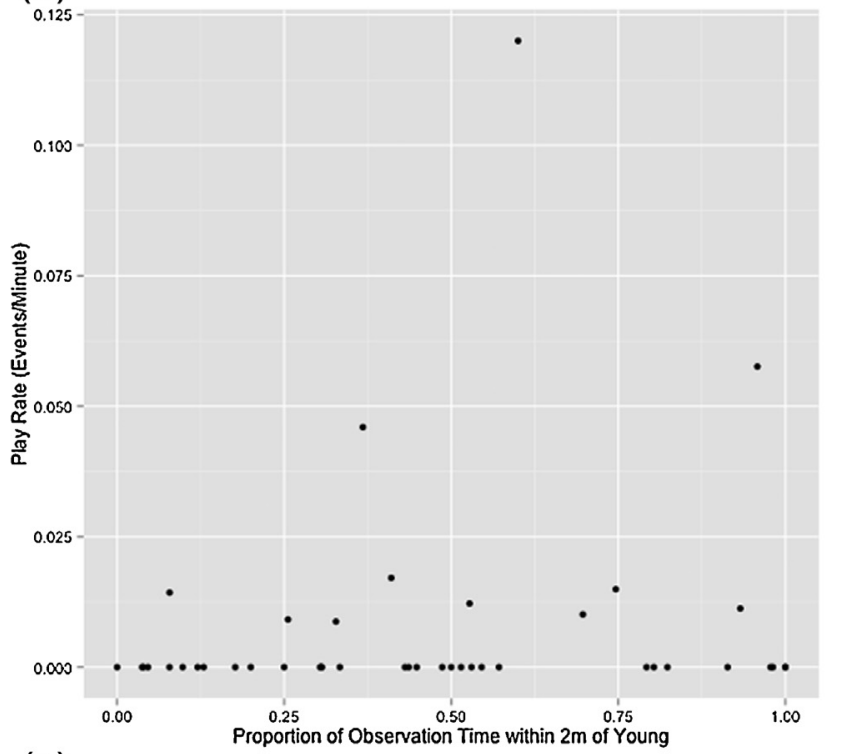

(c)

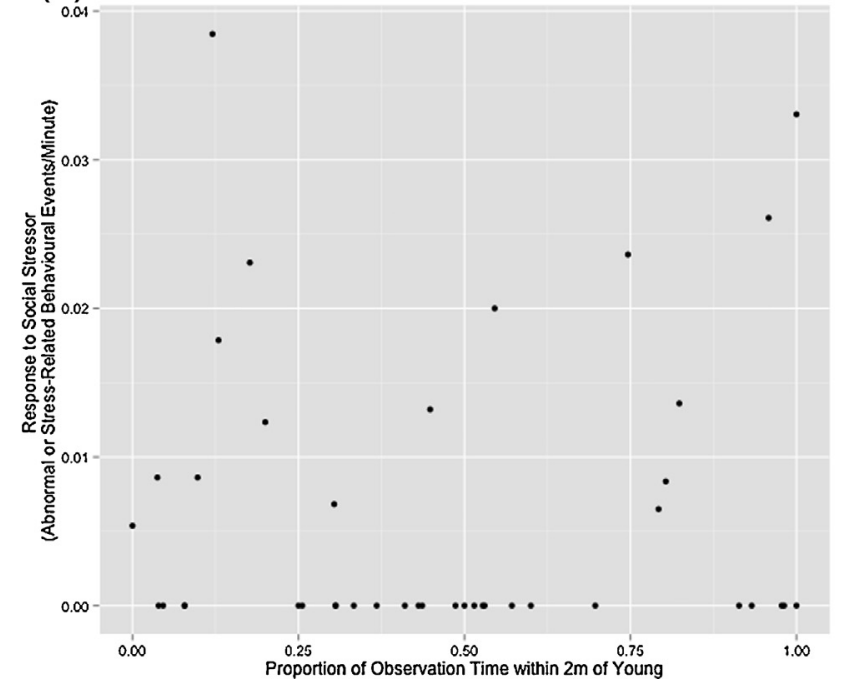

Fig. 3. a-c Scatterplots showing rates behaviour for females and the proportion of observation time females spent within $2 \mathrm{~m}$ of young. Each female is represented by a single point $(n=43)$. The extreme outlier reported in the results is excluded from Fig. 3c to improve visualization. Proportion of observation time in proximity to young was not found to be a significant predictor of any of these behavioural measures (all $P>0.4$ ).
One surprising result to emerge from this investigation is that captive-born/mother-reared adult females showed more abnormal or stress-related behaviours during the period preceding group feeding in a limited space (the social challenge) than their wildborn counterparts. Upon further inspection of the data it was clear that the predominant behaviour driving this difference was coprophagy. Coprophagy is an interesting behaviour as it is often considered abnormal and indicative of compromised welfare, yet it is under increasing scrutiny as a welfare indicator (Freeman and Ross, 2014; Hook et al., 2002; Hopper et al., 2016). The occurrence of coprophagy is not abnormal in the sense that it is within the behavioural repertoire of wild populations (Goodall, 1986; Nishida et al., 1999; Payne et al., 2008) though it is more prevalent in captive populations. This finding also replicates results indicating that coprophagy is more often expressed by captive-born, motherreared individuals than wild-born, human-reared individuals (Nash et al., 1999; Bloomsmith et al., 2006) further suggesting that the prevalence of this behaviour may not be indicative of poor welfare.

Although the findings here may not readily generalize to other species, the approach may serve as a basis for designing research to investigate the relationship between welfare and reproduction in other species. This study has attempted to contribute to our understanding of how controlling reproduction in captivity may impact welfare at an individual level. We have not addressed how contraceptives may impact the long-term reproductive potential of individuals or populations (Penfold et al., 2014). It will be important to investigate how different reproductive management strategies impact individual health, individual behaviour and group social dynamics before recommending reproductive management strategies for captive populations.

\section{Conclusions}

This study investigated whether rearing or associating with young was associated with measurable differences in the welfare of captive female chimpanzees. The results do not support the hypothesis that reproduction improves welfare for reproductively mature females, nor do they support the hypothesis that proximity to young improves welfare for reproductively mature females. These findings should be taken as preliminary evidence until additional welfare indicators are incorporated and the sample is expanded. These findings have important management implications, as they suggest that if confirmed, managers need not allow breeding to enhance welfare.

\section{Acknowledgements}

We thank Innocent Mulenga, the CWOT chimpanzee caretakers and Board of Trustees, the Chimfunshi Research Advisory Board, and the Zambian Wildlife Authority. We are grateful to Elizabeth Lonsdorf, Jeroen Stevens and two anonymous reviewers for providing feedback and thoughtful discussion on earlier versions of this manuscript, and to Daniel J. Acheson for statistical advice. We thank the Technical Group of the MPI for Psycholinguistics for their support. VW was funded by a BBSRC DTP Studentship and Travel Grant.

\section{Appendix A. Supplementary data}

Supplementary data associated with this article can be found, in the online version, at http://dx.doi.org/10.1016/j.applanim.2016. 05.014. 


\section{References}

Ballou, J.D., Lees, C., Faust, L.J., Long, S., Lynch, C., Bingaman Lackey, L., Foose, T.J., 2010. Demographic and genetic management of captive populations. In: Kleiman, D., Thompson, K., Baer, C. (Eds.), Wild Mammals in Captivity: Principles and Techniques for Zoo Management. , second ed. University of Chicago Press, pp. 219-252.

Bates, D., Maechler, M., Bolker, B., 2014. Ime4: Linear mixed-effects models using Eigen and S4. R Package Version 1.7.

Bethell, E.J., 2015. A how-to guide for designing judgment bias studies to assess captive animal welfare. J. Appl. Anim. Welf. Sci. 18, S18-S42.

Biro, D., Humle, T., Koops, K., Sousa, C., Hayashi, M., Matsuzawa, T., 2010. Chimpanzee mothers at Bossou, Guinea carry the mummified remains of their dead infants. Curr. Biol. 20, R351-R352.

Bloomsmith, M.A., Baker, K.C., Ross, S.R., Lambeth, S.P., 2006. Early rearing conditions and captive chimpanzee behavior: some surprising findings. In: Nursery Rearing of Nonhuman Primates in the 21st Century. Springer, pp 289-312.

Boccia, M.L., Laudenslager, M.L., Reite, M.L., 1995. Individual differences in macaques' responses to stressors based on social and physiological factors: implications for primate welfare and research outcomes. Lab. Anim. 29, 250-257.

Boissy, A., Manteuffel, G., Jensen, M.B., Moe, R.O., Spruijt, B., Keeling, L.J., Winckler, C., Forkman, B., Dimitrov, I., Langbein, J., Bakken, M., Veissier, I., Aubert, A., 2007. Assessment of positive emotions in animals to improve their welfare. Physiol. Behav. 92, 375-397.

Clubb, R., Mason, G.J., 2003. Animal welfare: captivity effects on wide-ranging carnivores. Nature 425, 473-474.

Clubb, R., Mason, G.J., 2007. Natural behavioural biology as a risk factor in carnivore welfare: how analysing species differences could help zoos improve enclosures. Appl. Anim. Behav. Sci. 102, 303-328.

Cronin, K.A., van Leeuwen, E.J.C., Mulenga, I.C., Bodamer, M.D., 2011. Behavioral response of a chimpanzee mother toward her dead infant. Am. J. Primatol. 73, 415-421.

Cronin, K.A., van Leeuwen, E.J.C., Vreeman, V., Haun, D.B.M., 2014. Population-level variability in the social climates of four chimpanzee societies. Evol. Hum. Behav. 35, 389-396.

Dawkins, M.S., 1998. Evolution and animal welfare. Q. Rev. Biol., 305-328.

Freeman, H.D., Ross, S.R., 2014. The impact of atypical early histories on pet or performer chimpanzees. PeerJ 2, e579.

Ghobrial, L., Lankester, F., Kiyang, J.A., Akih, A.E., De Vries, S., Fotso, R., Gadsby, E.L., Jenkins Jr., P.D., Gonder, M.K., 2010. Tracing the origins of rescued chimpanzees reveals widespread chimpanzee hunting in Cameroon. BMC Ecol. 10, 1-15.

Goodall, J., 1986. The Chimpanzees of Gombe: Patterns of Behavior. Belknap Press, Cambridge, MA.

Held, S.D., Špinka, M., 2011. Animal play and animal welfare. Anim. Behav. 81, 891-899.

Hirata, S., 2009. Chimpanzee social intelligence: selfishness, altruism, and the mother-infant bond. Primates 50, 3-11.

Hook, M.A., Lambeth, S.P., Perlman, J.E., Stavisky, R., Bloomsmith, M.A., Schapiro, S.J., 2002. Inter-group variation in abnormal behavior in chimpanzees (Pan troglodytes) and rhesus macaques (Macaca mulatta). Appl. Anim. Behav. Sci. 76, $165-176$.

Hopper, L.M., Freeman, H.D., Ross, S.R., 2016. Reconsidering coprophagy as an indicator of negative welfare for captive chimpanzees using a bottom-up approach. Appl. Anim. Behav. Sci. 176, 112-119.

Hrdy, S.B., 1976. Care and exploitation of nonhuman primate infants by conspecifics other than the mother. Adv Stud. Behav. 6, 101-158.

Lehmann, J., Boesch, C., 2009. Sociality of the dispersing sex: the nature of social bonds in West African female chimpanzees, Pan troglodytes. Anim. Behav. 77, 377-387.

Lehmann, J., Fickenscher, G., Boesch, C., 2006. Kin biased investment in wild chimpanzees. Behaviour 143, 931-955.

Leus, K., Traylor-Holzer, K., Lacy, R., 2011. Genetic and demographic population management in zoos and aquariums: recent developments, future challenges and opportunities for scientific research. Int. Zoo Yearb. 45, 213-225.

Llorente, M., Riba, D., Ballesta, S., Feliu, O., Rostán, C., 2015. Rehabilitation and socialization of chimpanzees (Pan troglodytes) used for entertainment and as pets: an 8-year study at fundació mona. Int. J. Primatol. 36, 605-624.

Mason, G., Mendl, M., 1993. Why is there no simple way of measuring animal welfare? Anim. Welfare 2, 301-319.
Matsuzawa, T., 1997. The death of an infant chimpanzee at Bossou, Guinea. Pan Afr. News, 4.

Mellor, D.J., Patterson-Kane, E., Stafford, K.J., 2009. The Sciences of Animal Welfare. John Wiley \& Sons.

Mellor, D.J., 2015. Positive animal welfare states and reference standards for welfare assessment. New Zeal. Vet. J. 63, 17-23.

Moberg, G.P., 2000. Biological response to stress: implications for animal welfare. In: Moberg, G.P., Mench, J.A. (Eds.), The Biology of Animal Stress: Basic Principles and Implications for Animal Welfare. CABI Publishing, New York, pp. $1-21$.

Murray, C.M., Lonsdorf, E.V., Stanton, M.A., Wellens, K.R., Miller, J.A., Goodall, J., Pusey, A.E., 2014. Early social exposure in wild chimpanzees: mothers with sons are more gregarious than mothers with daughters. Proc. Natl. Acad. Sci. U. S. A. $111,18189-18194$.

Nash, L.T., Fritz, J., Alford, P.A., Brent, L., 1999. Variables influencing the origins of diverse abnormal behaviors in a large sample of captive chimpanzees (Pan troglodytes). Am. J. Primatol. 48, 15-29.

Nishida, T., Kano, T., Goodall, J., McGrew, W.C., Nakamura, M., 1999. Ethogram and ethnography of mahale chimpanzees. Anthropol. Sci. 107, 141-188.

Nishida, T., 2011. Chimpanzees of the Lakeshore: Natural History and Culture at Mahale. University Press, Cambridge.

Palme, R., 2012. Monitoring stress hormone metabolites as a useful: non-invasive tool for welfare assessment in farm animals. Anim. Welf. 21, 331-337.

Payne, C.L.R., Webster, T.H., Hunt, K.D., 2008. Coprophagy by the semi-habituated chimpanzees of Semliki, Uganda. Pan Afr. News 15, 29-32.

Penfold, L.M., Powell, D., Traylor-Holzer, K., Asa, C.S., 2014. Use it or lose it: characterization: implications and mitigation of female infertility in captive wildlife. Zoo Biol. 33, 20-28.

Plowman, A.B., Jordan, N.R., Anderson, N., Condon, E., Fraser, O., 2005. Welfare implications of captive primate population management: behavioural and psycho-social effects of female-based contraception, oestrus and male removal in hamadryas baboons (Papio hamadryas). Appl. Anim. Behav. Sci. 90, 155-165.

Pomerantz, O., Terkel, J., 2009. Effects of positive reinforcement training techniques on the psychological welfare of zoo-housed chimpanzees (Pan troglodytes). Am. J. Primatol. 71, 687-695.

Pomerantz, O., Meiri, S., Terkel, J., 2013. Socio-ecological factors correlate with levels of stereotypic behavior in zoo-housed primates. Behav. Process. 98, 85-91.

Powell, D., 2014. The role of management euthanasia in population sustainability and animal welfare. In: Presented at the American Association of Zoo Veterinarians, Orlando,FL, USA.

Pusey, A.E., Schroepfer-Walker, K., 2013. Female competition in chimpanzees. Philos. Trans. R. Soc. B 368, 20130077.

Pusey, A.E., 1983. Mother-offspring relationships in chimpanzees after weaning. Anim. Behav. 31, 363-377.

R Core Team, 2014. R: A Language and Environment for Statistical Computing. R Core Team, Vienna, Austria, Retrieved from http://www.R-project.org.

Ron, T., McGrew, W.C., 1988. Ecological assessment for a chimpanzee rehabilitation project in Northern Zambia. Primate Conservation 9, 37-41.

Silk, J.B., 1999. Why are infants so attractive to others?: The form and function of infant handling in bonnet macaques. Anim. Behav. 57, 1021-1032.

Stanton, M.A., Heintz, M.R., Lonsdorf, E.V., Santymire, R.M., Lipende, I., Murray, C.M., 2015. Maternal behavior and physiological stress levels in wild chimpanzees (Pan troglodytes schweinfurthii). Int. J. Primatol. 36, 473-488.

Thoits, P.A., 2011. Mechanisms linking social ties and support to physical and mental health. J. Health Soc. Behav. 52, 145-161.

Uchino, B.N., Cacioppo, J.T., Kiecolt-Glaser, J.K., 1996. The relationship between social support and physiological processes: a review with emphasis on underlying mechanisms and implications for health. Psychol. Bull. 119, 488.

van Leeuwen, E.J.C., Cronin, K.A., Haun, D.B.M., Mundry, R., Bodamer, M.D., 2012. Neighbouring chimpanzee communities show different preferences in social grooming behaviour. P. R. Soc. B: Biol. Sci. 279, 4362-4367.

Vestergaard, K.S., Skadhauge, E., Lawson, L.G., 1997. The stress of not being able to perform dustbathing in laying hens. Physiol. Behav. 62, 413-419.

Wobber, V., Hare, B., Maboto, J., Lipson, S., Wrangham, R., Ellison, P.T., 2010. Differential changes in steroid hormones before competition in bonobos and chimpanzees. Proc. Natl. Acad. Sci. U. S. A. 107, 12457-12462. 